\title{
Dependence as a unifying construct in defining Alzheimer's disease severity
}

\author{
Trent McLaughlin ${ }^{\mathrm{a}}$, Howard Feldman ${ }^{\mathrm{b}}$, Howard Fillit ${ }^{\mathrm{c}}$, Mary Sano ${ }^{\mathrm{d}}$, Frederick Schmitt ${ }^{\mathrm{e}}$, \\ Paul Aisen ${ }^{\mathrm{f}}$, Christopher Leibman ${ }^{\mathrm{a}, *}$, Lisa Mucha ${ }^{\mathrm{g}}$, J. Michael Ryan ${ }^{\mathrm{g}}$, Sean D. Sullivan ${ }^{\mathrm{h}}$, \\ D. Eldon Spackman ${ }^{\mathrm{i}}$, Peter J. Neumann ${ }^{\mathrm{j}}$, Joshua Cohen ${ }^{\mathrm{j}}$, Yaakov Stern ${ }^{\mathrm{k}}$ \\ ${ }^{a}$ Janssen Alzheimer Immunotherapy Research \& Development, South San Francisco, CA, USA \\ ${ }^{b}$ Division of Neurology, University of British Columbia, Vancouver, BC, Canada; Neuroscience Global Clinical Research, \\ Bristol-Myers Squibb, Wallingford CT, USA; and Department of Neurology, Yale University, New Haven, CT, USA \\ ${ }^{c}$ Department of Geriatrics and Adult Development, Mount Sinai School of Medicine, New York, NY, USA \\ ${ }^{d}$ Mount Sinai School of Medicine, New York, NY, USA \\ ${ }^{e}$ Sanders-Brown Center on Aging, University of Kentucky, Lexington, KY, USA \\ ${ }^{f}$ Department of Neurosciences, University of California, San Diego, San Diego, CA, USA \\ ${ }^{g}$ Pfizer Inc., Collegeville, PA, USA \\ ${ }^{h}$ Department of Pharmacy, University of Washington, Seattle, WA, USA \\ ${ }^{i}$ Centre for Health Economics, University of York, York, United Kingdom \\ ${ }^{j}$ Center for the Evaluation of Value and Risk in Health, Institute for Clinical Research and Health Policy Studies, Tufts Medical Center, Boston, MA, USA \\ ${ }^{k}$ Taub Institute for Research on Alzheimer's Disease and the Aging Brain, Columbia University Medical Center, New York, NY, USA
}

\begin{abstract}
This article reviews measures of Alzheimer's disease (AD) progression in relation to patient dependence and offers a unifying conceptual framework for dependence in AD. Clinicians typically characterize $\mathrm{AD}$ by symptomatic impairments in three domains: cognition, function, and behavior. From a patient's perspective, changes in these domains, individually and in concert, ultimately lead to increased dependence and loss of autonomy. Examples of dependence in AD range from a need for reminders (early AD) to requiring safety supervision and assistance with basic functions (late AD). Published literature has focused on the clinical domains as somewhat separate constructs and has given limited attention to the concept of patient dependence as a descriptor of AD progression. This article presents the concept of dependence on others for care needs as a potential method for translating the effect of changes in cognition, function, and behavior into a more holistic, transparent description of AD progression.
\end{abstract}

(C) 2010 The Alzheimer's Association. All rights reserved.

Keywords:

Alzheimer's disease; Dementia; Functional impairment; Dependence; Disease progression

\section{Introduction}

Alzheimer's disease (AD), the most common form of dementia, is a progressive neurodegenerative disorder characterized by loss of memory and cognition, declining ability to perform activities of daily living (ADL), changes in personality and behavior, and increased use of health care resources and medical services. An estimated 27 million persons worldwide are currently living with $\mathrm{AD}$; this number

*Corresponding author. Tel.: 650-794-2534; Fax: 650-794-2504.

E-mail address: cleibman@janimm.com. is expected to quadruple to more than 106 million by 2050 , with 1 in 85 persons living with the disease [1,2]. In addition, $\mathrm{AD}$ places a considerable economic burden on the families of patients and on society. In the United States alone, AD is estimated to cost approximately $\$ 80$ billion per year, making it this country's third most costly disease [3].

$\mathrm{AD}$ can be described in a variety of ways. Clinicians tend to focus on cognition, function, or behavior in their descriptions (with each specialty selecting its preferred construct and measurement). The cognitive feature that is most commonly associated with the disease is memory impairment, although decision-making, judgment, spatial 
orientation, thinking/reasoning, and verbal communication might also be affected. Functional impairment in AD is typically referred to as disability in everyday functioning that results primarily from cognitive impairment, with notable losses in the ability to perform ADL. In addition, changes in personality and behavior are also common in patients with $\mathrm{AD}$ and might include aggression, wandering, apathy, and motor restlessness. These changes can be socially disruptive, can create high levels of caregiver stress and burden, and can also affect a patient's ability to perform ADL [4].

Few attempts have been made to integrate and model the domains of cognition, function, and behavior [5,6]. Earlier attempts to describe the progression of $\mathrm{AD}$ have focused primarily on discrete measures of cognitive function [7]. Although changes in cognition are the hallmark of dementia, especially in early disease, they are not the only symptom and, from an economic perspective, are not the sole drivers of the use of resources such as caregiver time, medical care, and nursing home placement [8].

Furthermore, as noted by Loveman et al [9], the literature provides limited and conflicting information on typical AD progression pathways in each of the three domains, and the variety of discrete measures that are used to describe disease-associated changes might further complicate models of progression. In addition, the method used to track the progression of $\mathrm{AD}$ might affect how patients are treated during the course of the disease and whether the treatments are viewed as successful [10]. For example, after attempting appropriate care of an $\mathrm{AD}$ patient who is repetitive and agitated, clinicians might opt to prescribe a medication that causes sedation. If this intervention is assessed strictly on the basis of agitation, it might be considered a success, even though the lives of both the patient and caregiver might now be less rewarding [11]. Because patients often experience different levels of disrupted behavior during the course of $A D$, the challenge is to manage behavioral decline without adversely affecting the functional and cognitive abilities of the patient at the time of the behavioral disturbances [10]. Tracking the progression of $\mathrm{AD}$ by focusing on a single aspect of the disease (eg, behavior) might mean that other important aspects (eg, function, cognition) might not be sufficiently addressed. A broader measure or concept of the overall impact of AD progression would address this issue by reflecting at least some of the negative effects of pharmacologic treatment as well as the positive outcomes.

A broader measurement of $\mathrm{AD}$ progression would also better integrate the concerns of individuals who are directly affected by the disease, specifically the patients and their loved ones. Although cognitive test scores provide clinicians with quantitative measures of memory and other mental functions, persons with $\mathrm{AD}$ might be more concerned with the overall effect of the disease than with its impact on individual domains $[12,13]$. Likewise, individuals who are concerned with resource allocation and health care costs tend to measure $\mathrm{AD}$ progression in terms of the patient's direct health care costs as well as living arrangements (eg, home versus an assisted living facility versus a nursing facility); living arrangements are easily assessed, and costs can be easily differentiated across locations. However, a patient's living situation is a function of multiple factors that might or might not be related to the severity of $\mathrm{AD}$. As a result, living environments do not provide a transparent, meaningful description of the overall impact of the disease for patients, caregivers, or clinicians. Although alternative measures of caregiver burden, such as the Zarit Burden Interview [14], provide a broad indicator of the effect of caregiving, these tools do not explicitly measure changes in patient disease severity in a transparent manner. In other words, a useful measure of $\mathrm{AD}$ progression must not only be broad, but it must also convey the effect of $\mathrm{AD}$ progression in a way that is meaningful to multiple audiences.

We propose in this article that dependence, or the level of assistance required by a patient with $\mathrm{AD}$, should be used as a construct for assessing the effect of $\mathrm{AD}$ treatment. Its correlate, independence, is an attractive measure for assessing disease progression because it has been shown to decline over time [15], is associated with other domains such as cognition and/or function [16], and is easily assessed/measured during both short and long periods. Similarly, a patient's level of dependence logically is related (directly and indirectly) to the degree of impairment in the individual domains of cognition, function, and behavior as well as to other factors that limit a patient's abilities. Mapping of AD progression as stages of increasing dependence on others would provide patients, families, and other decision makers with a better idea of current and future service needs and help quantify the impact of any treatments intended to delay this progression.

Describing AD progression as a process of increasing dependence on others would not replace current (or future) clinical measures (cognitive, functional, behavioral), but instead it would be a complementary measure that would allow translation of those end points into a common language for nonclinical audiences to use when they assess the impact of $\mathrm{AD}$ and the potential benefits of interventions. Thus, it might be beneficial to include a measure of dependence alongside clinical end points in clinical trials, descriptive studies, registries, and other types of studies that explore $\mathrm{AD}$ and the effect of its treatment. Furthermore, continued discussion of such a concept in the scientific literature would be of value to clinicians who are not currently involved in clinical trials but are responsible for the day-to-day care of AD patients and their loved ones.

The remainder of this article discusses the concept of dependence and reviews the literature on the subject as an initial attempt to explore the usefulness of characterizing AD progression in terms of increasing dependence.

Promoting independence or avoiding increased dependence previously has been highlighted as a worthy goal for the field of dementia care [17]. However, the multiplicity of terms, tools, and operational definitions used to describe and measure dependence has limited the construct's 
effectiveness as a measure of both $\mathrm{AD}$ progression and therapeutic impact.

If dependence is to be accepted as a measure of the impact of $\mathrm{AD}$ progression, some degree of consensus must be reached on the appropriate terminology and on its relationship to other constructs, its operational definition, and the instruments used to measure it. For example, dependence, as a construct, should reflect the level of assistance needed by a patient, not necessarily the level of assistance that is provided. Dependence differs from measures of care service (eg, the amount of caregiver time provided), which reflect not only patient need but also constraints on supply (eg, amount of caregiver time available, availability of care facilities, and patient and family financial resources). In this article, dependence is defined as the amount of care required from others (according to text from the Dependence Scale [16]). This definition was selected over a dichotomous measure (eg, independent versus dependent [18]) because focusing on overall care needs allows for translation of multiple facets of the disease into a single measure, and using a scale with multiple levels provides more granularity for measuring changes over time. Our primary objective was to review the current literature on dependence to establish a consensus on and recommendations for incorporating dependence into $\mathrm{AD}$ therapeutic and outcomes research. We describe the concept of dependence in $\mathrm{AD}$ and its relationship to other commonly used $\mathrm{AD}$ domains/measures (ie, cognition, function, and behavior).

\section{Dependence: Conceptual framework}

Dependence in $\mathrm{AD}$ can be characterized as the measurable impact of changes in cognition, function, and behavior that result in an increased need for assistance. Although these domains measure different aspects of the impact of $\mathrm{AD}$, they have an inter-related and aggregate effect (Fig. 1). Cognitive deficits are initially subtle/mild effects that might require patients to seek assistance with social activities (this need for assistance might correspond to limitations in handling community affairs and home and hobbies as measured on the Clinical Dementia Rating scale [19]). Over time, cognitive deficits might lead to increased reliance on others for coping with memory-related impairments (eg, keeping appointments), disorientation (including maintaining proper tempo$\mathrm{ral} / \mathrm{spatial}$ orientation), executive impairments that lessen the patient's ability to manage finances or medications, and finally, apraxia (ie, difficulty executing complex coordinated movements), which might be associated with memory, judgment and problem solving, and orientation categories on the Clinical Dementia Rating [19]. Functional impairment, which is operationally defined as a patient's inability to perform specific activities, directly translates to dependence on others and to the loss of functional autonomy. When patients with $\mathrm{AD}$ can no longer dress themselves, they will be dependent on caregivers to complete parts of their everyday routines. The behavioral sequelae of $\mathrm{AD}$ vary but might

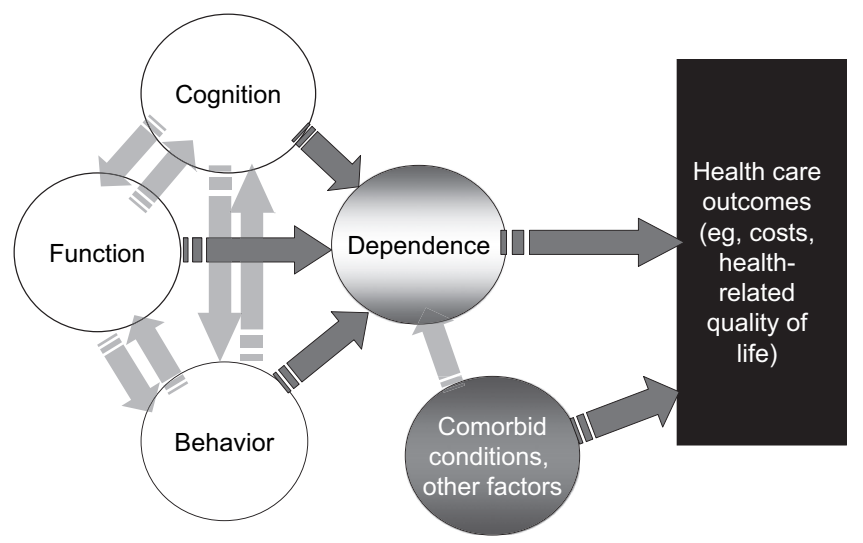

Fig. 1. Dependence: Conceptual framework.

include changes such as apathy, irritability, depression, anxiety, restlessness, agitation, and aggression. For example, wandering often leads to increased personal risk of injury and the need for management strategies that involve the extended caregiving community. Although behavioral symptoms vary among individuals, they might generally lead to increased assistance needs (eg, supervision to minimize harm to the patient or, possibly, other individuals). For example, Murman et al [20] found that neuropsychiatric symptoms, as measured by the Neuropsychiatric Inventory, were significantly correlated with a measure of dependence (the Dependence Scale), with changes in the Neuropsychiatric Inventory score accounting for $22 \%$ of the variation in dependence level.

Dependence can also be depicted to share a temporal relationship with changes in cognition, function, and behavior. As Fig. 2 illustrates, the relative contributions of cognitive, functional, and behavioral impairments on the overall level of dependence would be expected to change over time, as the disease progresses and as the relationship between the patient and his or her environment changes. For example, in early $\mathrm{AD} /$ mild cognitive impairment, changes in cognition (eg, the patient becomes forgetful and/or confused in social situations) might be the primary contributor to changes in

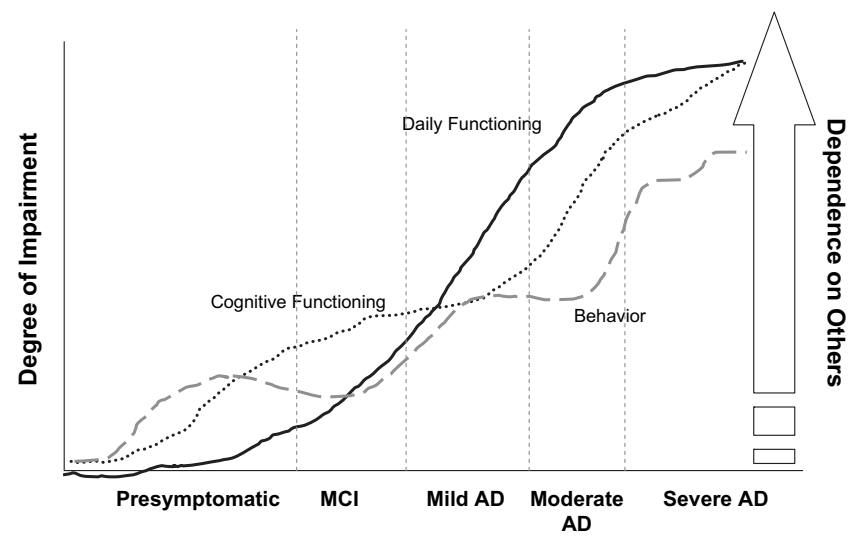

Fig. 2. Impacts of impairments in cognition, function, and behavior on patient dependence on others. 
the level of dependence. Functional impairment (eg, related to driving, financial management) would make only a minimal contribution to increased dependence in the early stages but would be expected to play a larger role with the passage of time and disease progression. Behavioral issues, on the other hand, tend to be more difficult to predict; even patients with mild cognitive impairment might experience depression, apathy, or anxiety, which might make patients more difficult to care for and might lead to a decrease in their ability to care for themselves and therefore to increased dependence on others. In all cases, the trend is toward greater dependence on others, whether it is primarily caused by changes in cognition, function, or behavior.

It should be noted that a person's level of dependence might be further influenced by factors other than those related to AD severity. For example, comorbid conditions, physical handicaps, or environmental factors might play an important role in defining an overall level of dependence on others for care needs. However, the primary focus of this article is to explore the concept of dependence as it relates to $\mathrm{AD}$, ie, how the definition of dependence could be operationalized to focus primarily on the relationship between changes in $\mathrm{AD}$ symptomatology and changes in patient reliance on others for care needs. Furthermore, for the purpose of this discussion, dependence is considered to be a separate construct from disability; the latter is a broader measure of the general health and well-being of a person beyond merely his or her AD symptomatology/severity.

Previous attempts to characterize dependence either have focused on function or have defined a small number of discrete stages (eg, independent versus dependent), whereas the dependence framework described herein has the advantage of being able to characterize the complete range of the disease's impact and severity. Because the transition from completely independent to completely dependent occurs on a continuum, measures of dependence should not be characterized as a dichotomous quantity or as an arbitrarily limited number of discrete levels, as has been the case with previous measures [15,18,21-23]. Furthermore, when changes in cognition, function, and behavior are translated into a single overall measure of disease impact, patients, caregivers, and providers might gain a clearer understanding of the typical course of the disease.

\section{Discussion of independence/dependence in the literature}

The idea of associating AD with the loss of independence is not new. A number of researchers have described AD progression in this way. For example, Bullock and Hammond [24] described the natural course of $\mathrm{AD}$ as a gradual loss of independence, dividing it into four stages: mild (patient has cognitive deficits that might necessitate retirement from work, but he or she remains capable of living independently); moderate (need for assistance with ADL and personality changes mean that the patient might not be able to safely live alone); severe (patient has lost the ability to ambulate independently and can no longer eat without assistance); and for patients who live long enough, terminal, which is characterized by the inability to walk (even with assistance) or to communicate with others [24]. Much of this description comes from an earlier article by Volicer [25], who presented a similar description of progressive dementia.

Barbas and Wilde [26] reviewed the impact of dementia from a legal perspective and noted that the loss of competency, which typically occurs as the disease progresses beyond the early stages, creates unique challenges and interferes with a patient's ability to live independently. Finally, Woods [17] dedicated an entire article to the need for promoting well-being and independence among people with dementia and noted the lack of methods for measuring these traits in this population.

Although articles identifying loss of independence as an important feature of $\mathrm{AD}$ have been in the public domain for many years, the lack of a concise operational definition of dependence, as well as the lack of a specific measurement approach, has likely limited the attention that has been given to this concept. The next section provides an overview of instruments that have been developed to measure changes in dependence in patients with $\mathrm{AD}$.

\subsection{Broad measures of dependence: Published instruments}

A MEDLINE search of all indexed journals published in English from 1980 through 2008 was conducted by using the terms dementia, Alzheimer's disease, dependence, and independence. This initial query identified 521 potentially relevant articles containing these search terms. After excluding articles focused on alcohol or drug dependence and those that included the search terms in a way that was unrelated to the current review (eg, context dependent, $\mathrm{pH}$ dependent, independent variable), a working set of 98 articles remained.

Articles related to purely functional measures (eg, measured only ADL) were then excluded ( $n=41$, see Appendix), as were measures of subjective caregiver burden (eg, Zarit Burden Interview, $\mathrm{n}=10$; see Appendix), to focus primarily on instruments purported to measure the level of patient dependence on others for care needs.

Of the remaining 47 articles that discussed dependence/independence and dementia, a semistructured review of abstracts was conducted to further exclude articles that did not discuss specific instruments or research activities $(\mathrm{n}=$ 29; see Appendix), which left 18 articles that described some measure of dependence in dementia or AD.

The reference lists from articles obtained through the MEDLINE search were also reviewed for pertinent sources. This literature search indicated that relatively few instruments have been developed to measure dependence in patients with AD (Table 1) [15,16,18,27-34].

The Record of Independent Living (RIL) is a 37-item instrument designed to evaluate cognitive decline in elderly 
Table 1

Instruments for measuring degree of dependence

\begin{tabular}{|c|c|c|c|c|c|}
\hline Instrument & Target population & Administration & No. of items & Comment & Reference citation(s) \\
\hline ILS & $\begin{array}{l}\text { Patients with mild to } \\
\text { severe dementia }\end{array}$ & $\begin{array}{l}\text { Clinician-administered to } \\
\text { patient }\end{array}$ & 70 & $\begin{array}{l}\text { Includes several subscales } \\
\text { such as tests of } \\
\text { cognition and problem- } \\
\text { solving behaviors }\end{array}$ & $\begin{array}{l}\text { Loeb [28], Martin-Cook } \\
\text { et al [29], Revheim and } \\
\text { Medalia [30] }\end{array}$ \\
\hline BGP & $\begin{array}{l}\text { Patients with moderate to } \\
\text { severe dementia, } \\
\text { institutional setting }\end{array}$ & Nurse rating of patient & $\begin{array}{l}35 \text { (BGP-dependency: } \\
23 \text { items) }\end{array}$ & $\begin{array}{l}\text { Primary focus is } \\
\text { behavioral issues and } \\
\text { how they relate to care } \\
\text { needs in nursing home } \\
\text { patients }\end{array}$ & $\begin{array}{l}\text { Van der Kam et al [31], } \\
\text { Van de Winckel et al } \\
\text { [32] }\end{array}$ \\
\hline DS & $\begin{array}{l}\text { Patients with mild to } \\
\text { severe dementia in } \\
\text { a community or } \\
\text { institutional setting }\end{array}$ & Informant-completed & 13 & $\begin{array}{l}\text { Knowledgeable informant } \\
\text { estimates amount of } \\
\text { care needed, not } \\
\text { necessarily the amount } \\
\text { of care that is provided }\end{array}$ & $\begin{array}{l}\text { Brickman et al [15], Caro } \\
\text { et al [18], Holtzer et al } \\
\text { [33], Sarazin et al [34], } \\
\text { Stern et al [16] }\end{array}$ \\
\hline
\end{tabular}

patients [27]. The RIL has three sections (activities, communication, and behavior) and was designed to rectify the potentially excessive focus of other instruments on ADL. An exclusive focus on loss of the ability to perform ADL can be misleading because it ignores patients with $\mathrm{AD}$ who might have altered mental states that change their conduct, personality, or communication, but who have no physical disabilities. Instruments that essentially ignore these cognitive and behavioral changes might miss some of the earliest signs of a dementing illness [27]. However, acceptance of the RIL in the mainstream literature seems to be limited. In addition, no information is available on changes in RIL item scores over time. Also, the RIL does not provide any indication of hierarchy among items; the RIL does not distinguish complex capabilities (eg, managing one's finances) that AD typically compromises early in the disease process from more basic capabilities (eg, toileting) that typically are affected later on.

The Independent Living Scales (ILS) assessment was designed to provide a broad measure of dependence in patients with dementia by incorporating cognitive/reasoning skills in addition to physical measures $[28,30]$. The ILS is conducted by a clinician and consists of five subscales and two factor-analyzed subscales. The memory-orientation subscale evaluates an individual's ability to recall a list and recognize an object as well as his or her orientation to time and place. The managing money subscale includes concrete tasks such as monetary calculations. The managing home and transportation subscale assesses an individual's ability to use public transportation and to perform tasks involved in managing a home, such as using a telephone. An individual's awareness of health problems and potential safety hazards, as well as the ability to handle medical emergencies, is assessed on the health and safety subscale. Finally, attitudes and concerns regarding interpersonal relationships are assessed on the social adjustment subscale. The two factor-analyzed subscales (composed of items from all five aforementioned subscales) are the performanceinformation subscale and the problem-solving subscale.

The ILS differs from other instruments in that the scales are clinician-driven measures, requiring the patient to perform a number of tests that each take 30 to 45 minutes. To date, the ILS has not been widely used in populations with dementia, possibly because of the time required to administer the scales. Also, it is unclear how disease progression can be measured with the ILS, given the focus on task performance and the limited information on ordering/scoring of tests over time.

The Behavioral Rating Scale for Geriatric Patients (BGP) [31,32] was originally developed in The Netherlands in 1971 as an adaptation of an older scale. The BGP consists of 35 items covering six aspects of patients' behavior as it pertains to care in a nursing home setting: helplessness, aggressive behavior (eg, threatening behaviors such as beating or kicking), physical disability (eg, requirement for assistance with eating, incontinence, the need for restraints or supports to avoid falling), depressive behavior, mental disability (eg, paranoia), and inactivity (eg, daytime drowsiness, lack of involvement in useful activities). The items primarily focus on behaviors that would be problematic from a nursing care/assistance standpoint, such as additional supervision needs as a result of inappropriate behaviors or assistance with basic ADL, and are assessed by an informed respondent, typically a nurse or a family member.

The BGP-dependency subscale, which consists of a subset of the original 35 BGP items, has been used in the study of 
memantine in patients with moderately severe to severe $\mathrm{AD}$ [38]. Although the terms used to describe the BGP, especially the BGP-dependency subscale, are similar to the language used in this article (eg, care dependency, care needs), the BGP is focused primarily on patient behavior, and given the heavy attention paid to behaviors that are more prevalent in a nursing home situation, it is unlikely that the scale in its current form would be useful for a population with less severe AD.

The Nursing Care Dependency (NCD) scale differs from other measures of dependence in that it was developed on the basis of nursing theory and specifically assesses a patient's degree of reliance on nursing care [35-37]. The NCD is composed of 15 different dimensions of human need: eating and drinking, incontinence, body posture, mobility, day/night pattern, getting dressed and undressed, body temperature, hygiene, avoidance of danger, communication, contact with others, sense of rules and values, daily activities, recreational activities, and learning ability. A nurse who is directly involved in the care of the patient rates the patient's degree of dependence for each of these dimensions. In the short version of the NCD, a 5-point Likert scale is used to rate each dimension. The longer version of the NCD uses five written criteria, describing varying degrees of aid required by a patient, for each dimension of need. The nurse selects the criterion in each dimension that most accurately describes the patient's degree of dependence. By assessing the patient's degree of dependence on nursing care, the NCD allows nurses to better plan individualized patient care.

The primary objective of the Dependence Scale (DS), which is completed by a reliable informant such as a caregiver, is to measure the current level of care required by a patient [16]. The 13 items on the DS range from subtle forms of dependence, such as the need to be watched or accompanied outside, to more gross forms, such as the need for assistance in self-care activities. The instrument is hierarchical in nature, with the items representing increasing levels of assistance. For example, item A addresses the need for simple reminders or advice; item $\mathrm{D}$ addresses the ability to independently perform household chores; later items address the need for assistance with moving and tube feeding. Items $\mathrm{A}$ and $\mathrm{B}$ are scored on a 3 -point scale $(0=$ never, $1=$ occasionally, $2=$ frequently), items $\mathrm{C}$ through $\mathrm{M}$ are scored on a 2-point scale $(0=$ no, $1=$ yes $)$. The sum of the scores from the 13 items is used to characterize a patient's overall dependence, which is associated with the patient's living situation and has been correlated with, but is independent of, measures of cognition and function [15].

The DS has been used in a number of observational studies and in trials of AD treatments [15,20,33,34,39-41]. Considerable evidence also supports it as a measure of dependence (as the concept was described earlier), as characterized by deficits in cognition, function, and behavior. In an analysis of patients with AD in the Midwestern United States, Murman et al [20] found that dependence (as measured by the DS) was a statistically significant mediating/explanatory var- iable between various clinical measures and AD-related costs. In particular, measures of cognition, behavior, and other factors predicted a patient's dependence level, as measured by the DS, which in turn predicted the patient's total AD-related costs, explaining $40 \%$ of the variation.

\subsection{Dependence and economic evaluations of $A D$ treatments}

Attempts to quantify the economic benefits of the treatment of $\mathrm{AD}$ with acetylcholinesterase inhibitors or memantine primarily have focused on end points related to cognition and, rarely, function. However, dependence (or independence) has, on occasion, been used in economic evaluations to translate short-term treatment benefits into long-term consequences. For example, in their cost-effectiveness model of memantine in Finland, Francois et al [42] defined health states on the basis of physical dependence, place of residence, and cognitive function. One of the primary findings of this model was that memantine therapy was associated with approximately 4 extra months of independence. Caro et al [18] operationally defined dependent on the basis of two different measures: requirement for $>12$ hours of supervision or a DS dependence level $\geq 3$. Although this definition allowed for straightforward comparisons of resource use and quality of life for independent versus dependent patients and also allowed for calculation of time until a person was considered dependent, creating a dichotomous variable to describe what should be a continual process (ie, an AD patient typically is not independent one day and dependent the next) limits the utility of this measure for broader applications.

\section{Summary}

Measures currently used to assess AD treatment efficacy do not meaningfully describe the overall impact of the disease on patients and their loved ones. To provide a more complete picture of $\mathrm{AD}$, assessment measures should incorporate aspects of cognitive, functional, and behavioral impairments and present these factors in a way that multiple audiences can understand.

Previous research indicates that $\mathrm{AD}$ is strongly associated with increased dependence (reliance on others for care and basic needs). Dementia is also a risk factor for mortality in a variety of populations [43]. Compared with individuals without $\mathrm{AD}$, those with $\mathrm{AD}$ can expect to have shorter lives and spend a greater share of their remaining time dependent on others.

Previous attempts to describe AD progression in economic analyses have partially touched on the idea of dependence as it relates to living situation. For example, in the recent appraisal document from the United Kingdom's National Institute of Clinical Effectiveness (NICE) [44], a review of potential long-term benefits and costs of acetylcholinesterase inhibitor use was conducted by using a model based on patient care requirements, dichotomized 
into "not requiring full-time care" or "requiring full-time care." Although the NICE authors noted that this was a gross oversimplification of $\mathrm{AD}$, they also commented that patient care needs were the most transparent depiction of $\mathrm{AD}$ progression for determining economic impact. Therefore, further exploration of patient dependence or care needs with greater granularity might benefit agencies such as the NICE as they continue to evaluate $\mathrm{AD}$ therapies.

Further research on the concept of dependence might also provide a more comprehensive, meaningful, and consistent method for characterizing $\mathrm{AD}$ progression from the mild through the severe disease stages. Loss of independence, which is gradual during some periods but devastatingly fast at other times, begins early in the course of AD. Unlike many other chronic conditions, AD also affects caregivers and family members in the early stages of the disease, as patients become increasingly reliant on them. Affected individuals lose the ability to perform certain activities, require increased supervision, and eventually can no longer live on their own. This dependence might be an important factor in predicting patient disability, expenses, and caregiver stress throughout the course of the disease. Characterizing typical changes in dependence can help caregivers plan ahead.

Considering the link between patient dependence and the need for additional support or care, a measure of this construct presents a relatively straightforward way of translating clinical changes into units of economic relevance (ie, resource use and/or quality of life). Such a construct would be preferential to those used in previous attempts to model the relationship between cognition and economic consequences, in which the relationship was weak and difficult to describe, or even in multiattribute models, which, because of their complexity, are difficult to interpret and/or communicate. A model based on the concept of increasing dependence would be useful to policy makers and/or economists in that it might increase their confidence that changes in resource use and/or quality of life are indeed due to changes in the measure of AD progression. Such a model would also be useful to other audiences (eg, physicians, patients, caregivers) for which a clear description of the disease path and potential impact of intervention(s) is not currently available.

A potential limitation of using dependence as a measure of $\mathrm{AD}$ progression is that the amount of assistance required by a patient might be influenced by non-disease-related factors, including the individual's level of care or dependence at baseline. However, current measures of cognition and function have similar limitations. For example, measures of function that review specific activities (eg, meal preparation) assume a certain level of premorbid functioning that might not be appropriate for all individuals. Similarly, cognitive examinations that incorporate word lists or other memory tests assume a premorbid level of education and/or cognitive ability that might not apply to everyone. For all these measures, change from baseline level is the most important gauge of disease progression. Although individuals might be diag- nosed with $\mathrm{AD}$ at different levels of dependence (or cognition or function), their need for assistance should increase at similar rates as their disease progresses.

Another potential issue relates to who should rate a patient's dependence level. With the exception of the ILS and NCD Scale, most measures of dependence identified in the literature require input from an informant (usually a caregiver). Although a patient's primary caregiver should have the greatest insight into the patient's daily needs, an independent observer would be less likely to be personally affected by the patient's dependence. Congruence between caregiver and/or informant and independent observer assessments of patient dependence has not yet been established.

These limitations primarily relate to how to best operationalize the concept of dependence. All instruments that are currently available and are described in this article have potential limitations. For example, the BGP-Dependency and NCD scales were both developed for use in nursing homes and therefore focus primarily on severe AD. Information on the performance of the ILS and RIL and how scores on these instruments relate to conventional measures of cognition, function, or behavior is sparse or nonexistent; therefore, we cannot recommend either of these instruments for widespread use. More data have been published on the DS, but because this instrument was not developed by using standard psychometric techniques, we are unable to comment on its overall performance. Furthermore, the handling of individual items (eg, scoring of the first two items versus all later items) requires further investigation, as well as the grouping of certain elements into one item (eg, need for reminders with chores, shopping, playing games) and further clarification of the terms used to describe frequency of events (eg, occasionally $=$ once per month, frequently $=$ once per week). Thus, because the DS has the most supporting information, in our opinion it would be considered the most viable candidate of the instruments identified here. However, the DS still requires further investigation before it can be recommended for widespread use.

As evidenced by the paucity of instruments and the limited supporting data for the few available instruments, further developments in the measurement of dependence would be valuable. In particular, the development of a new instrument that incorporates the knowledge gained from the measures described herein, as well as from review of other measures of $\mathrm{AD}$ progression, would be a valuable addition to the field. Although it is beyond the scope of this article to develop and/ or test a new measure, the available data suggest that a hierarchical scale that encompasses the effect of cognition, function, and behavior during the entire disease course (ie, from early through late-stage disease), allows for measurement of the presence and frequency of symptoms, and is administered with minimal time burden on the clinician or caregiver would be optimal. Scoring should allow for calculation of an overall level of dependence that can be translated into a meaningful description of disease course and should also allow for flexibility and/or granularity around specific symptoms (eg, 
acknowledging that different symptoms or even different frequencies of the same symptom can be associated with different levels of dependence and support needs). Evidence to support the linkage between scores on this new scale and conventional measures of cognition or function would be useful in increasing confidence in its content validity.

$\mathrm{AD}$ is a devastating illness, not only for patients but also for those around them. The disease can have a variety of effects that might not be adequately reflected by conventional measures of cognition, function, or behavior. Instead, a more comprehensive view of the disease and its impact is needed to more appropriately describe its progression. Dependence (or loss of independence) is a potentially useful concept for describing disease progression in broader terms; decrements in each of the conventional measures can be associated with increased dependence, and the concept of lost independence corresponds to how patients and caregivers typically view the effect of AD. Measures of dependence might help clinicians better understand the health, economic, and pharmacoeconomic impact of AD. Potential measures of the concept of dependence have been suggested in this article. Additional work is needed to refine the concept and to further validate the current measures or develop new ones.

\section{Acknowledgments}

T. McLaughlin is an employee of Elan Corporation. H. Feldman is a paid consultant for Elan Pharmaceuticals, Inc, and Wyeth Pharmaceuticals; study investigator of a clinical trial sponsored by Elan Pharmaceuticals, Inc; employee of Bristol-Myers Squibb. H. Fillit is consultant for, grantee of, or honoraria from Eisai Inc; Elan Pharmaceuticals, Inc; Forest Laboratories; Neurochem; Novartis Pharmaceuticals; Ortho-McNeil Neurologics; Pfizer; and Sanofi-Aventis. M. Sano is a paid consultant for Elan Pharmaceuticals, Inc. C. Leibman is an employee of Elan Pharmaceuticals, Inc. L. Mucha and J. M. Ryan are employees of Wyeth Pharmaceuticals. S. Sullivan is a paid consultant for and training grant support from Elan Pharmaceuticals, Inc. D. E. Spackman is a paid consultant for and research grant support from Elan Pharmaceuticals, Inc. P. Neumann is a study investigator funded by Elan Pharmaceuticals, Inc. J. Cohen receives funding from Elan Pharmaceuticals, Inc. Y. Stern is a paid consultant for and study investigator funded by Elan Pharmaceuticals, Inc.

\section{References}

[1] Brookmeyer R, Johnson E, Ziegler-Graham K, Arrighi HM. Forecasting the global burden of Alzheimer's disease. Alzheimers Dement 2007;3:186-91.

[2] Hebert LE, Scherr PA, Bienias JL, Bennett DA, Evans DA. Alzheimer disease in the US population: prevalence estimates using the 2000 census. Arch Neurol 2003;60:1119-22.

[3] Hill J, Fillit H, Thomas SK, Chang S. Functional impairment, healthcare costs and the prevalence of institutionalisation in patients with
Alzheimer's disease and other dementias. Pharmacoeconomics 2006; 24:265-80

[4] Esiri MM. The basis for behavioural disturbances in dementia. J Neurol Neurosurg Psychiatry 1996;61:127-30.

[5] Ashford JW, Schmitt FA. Modeling the time-course of Alzheimer dementia. Curr Psychiatry Rep 2001;3:20-8.

[6] Ashford JW, Shan M, Butler S, Rajasekar A, Schmitt FA. Temporal quantification of Alzheimer's disease severity: time index model. Dementia 1995;6:269-80.

[7] Green C, Picot J, Loveman E, Takeda A, Kirby J, Clegg A. Modeling the cost effectiveness of cholinesterase inhibitors in the management of mild to moderately severe Alzheimer's disease. Pharmacoeconomics 2005;23:1271-82.

[8] Cohen JT, Neumann PJ. Decision analytic models for Alzheimer's disease: state of the art and future directions. Alzheimers Dement 2008; 4:212-22.

[9] Loveman E, Green C, Kirby J, Takeda A, Picot J, Payne E, et al. The clinical and cost-effectiveness of donepezil, rivastigmine, galantamine and memantine for Alzheimer's disease. Health Technol Assess 2006; 10:1-160. iii-iv, ix-xi.

[10] Schmitt FA, Wichems CH. A systematic review of assessment and treatment of moderate to severe Alzheimer's disease. Prim Care Companion J Clin Psychiatry 2006;8:158-69.

[11] Banerjee S. Commentary on "Health economics and the value of therapy in Alzheimer's disease": quality of life in dementia-development and use of a disease-specific measure of health-related quality of life in dementia. Alzheimers Dement 2007;3:166-71.

[12] Karlawish JH, Casarett DJ, James BD, Tenhave T, Clark CM, Asch DA. Why would caregivers not want to treat their relative's Alzheimer's disease? J Am Geriatr Soc 2003;51:1391-7.

[13] Karlawish JH, Zbrozek A, Kinosian B, Gregory A, Ferguson A, Low DV, et al. Caregivers' assessments of preference-based quality of life in Alzheimer's disease. Alzheimers Dement 2008;4:203-11.

[14] Zarit SH, Reever KE, Bach-Peterson J. Relatives of the impaired elderly: correlates of feelings of burden. Gerontologist 1980; 20:649-55.

[15] Brickman AM, Riba A, Bell K, Marder K, Albert M, Brandt J, et al. Longitudinal assessment of patient dependence in Alzheimer disease. Arch Neurol 2002;59:1304-8.

[16] Stern Y, Albert SM, Sano M, Richards M, Miller L, Folstein M, et al. Assessing patient dependence in Alzheimer's disease. J Gerontol 1994; 49:M216-22.

[17] Woods B. Promoting well-being and independence for people with dementia. Int J Geriatr Psychiatry 1999;14:97-105.

[18] Caro J, Ward A, Ishak K, Migliaccio-Walle K, Getsios D, Papadopoulos G, et al. To what degree does cognitive impairment in Alzheimer's disease predict dependence of patients on caregivers? BMC Neurol 2002;2:6.

[19] Morris JC. Clinical dementia rating: a reliable and valid diagnostic and staging measure for dementia of the Alzheimer type. Int Psychogeriatr 1997;9:173-6. discussion 177-8.

[20] Murman DL, Von Eye A, Sherwood PR, Liang J, Colenda CC. Evaluated need, costs of care, and payer perspective in degenerative dementia patients cared for in the United States. Alzheimer Dis Assoc Disord 2007;21:39-48.

[21] Hebert R, Carrier R, Bilodeau A. The functional autonomy measurement system (SMAF): description and validation of an instrument for the measurement of handicaps. Age Ageing 1988;17:293-302.

[22] Kurz X, Scuvee-Moreau J, Rive B, Dresse A. A new approach to the qualitative evaluation of functional disability in dementia. Int J Geriatr Psychiatry 2003;18:1050-5.

[23] Livingston G, Katona C, Roch B, Guilhaume C, Rive B. A dependency model for patients with Alzheimer's disease: its validation and relationship to the costs of care-the LASER-AD study. Curr Med Res Opin 2004;20:1007-16.

[24] Bullock R, Hammond G. Realistic expectations: the management of severe Alzheimer disease. Alzheimer Dis Assoc Disord 2003;17 :S80-5. 
[25] Volicer L. Management of severe Alzheimer's disease and end-of-life issues. Clin Geriatr Med 2001;17:377-91.

[26] Barbas NR, Wilde EA. Competency issues in dementia: medical decision making, driving, and independent living. J Geriatr Psychiatry Neurol 2001;14:199-212.

[27] Weintraub S. The record of independent living: an informant-completed measure of activities of daily living and behavior in elderly patients with cognitive impairment. Am J Alzheimers Dis Other Dement 1986;1:35-9.

[28] Loeb PA. ILS: Independent Living Scales manual. San Antonio, TX: Psychological Corp: Harcourt Brace Jovanovich; 1996.

[29] Martin-Cook K, Davis BA, Hynan LS, Weiner MF. A randomized, controlled study of an Alzheimer's caregiver skills training program. Am J Alzheimers Dis Other Dement 2005;20:204-10.

[30] Revheim N, Medalia A. The Independent Living Scales as a measure of functional outcome for schizophrenia. Psychiatr Serv 2004; 55:1052-4.

[31] van der Kam P, Mol F, Wimmers MFGH. Behavioral Rating Scale for Geriatric Patients (BGP) [in Dutch]. Deventer, The Netherlands: Van Loghum Slaterus; 1971.

[32] van de Winckel A, Feys H, de Weerdt W, Dom R. Cognitive and behavioural effects of music-based exercises in patients with dementia. Clin Rehabil 2004;18:253-60.

[33] Holtzer R, Wegesin DJ, Albert SM, Marder K, Bell K, Albert M, et al. The rate of cognitive decline and risk of reaching clinical milestones in Alzheimer disease. Arch Neurol 2003;60:1137-42.

[34] Sarazin M, Stern Y, Berr C, Riba A, Albert M, Brandt J, et al. Neuropsychological predictors of dependency in patients with Alzheimer disease. Neurology 2005;64:1027-31.

[35] Dijkstra A, Buist G, Dassen T. A criterion-related validity study of the nursing-care dependency (NCD) scale. Int J Nurs Stud 1998;35: $163-70$.

[36] Dijkstra A, Buist G, Dassen T. Operationalization of the concept of "nursing care dependency" for use in long-term care facilities. Aust N Z J Ment Health Nurs 1998;7:142-51.

[37] Dijkstra A, Buist G, Moorer P, Dassen T. Construct validity of the Nursing Care Dependency Scale. J Clin Nurs 1999;8:380-8.

[38] Tariot PN, Farlow MR, Grossberg GT, Graham SM, McDonald S, Gergel I, et al. Memantine treatment in patients with moderate to severe Alzheimer's disease already receiving donepezil: a randomized controlled trial. JAMA 2004;291:317-24.

[39] Sano M, Ernesto C, Thomas RG, Klauber MR, Schafer K, Grundman M, et al. A controlled trial of selegiline, alpha-tocopherol, or both as treatment for Alzheimer's disease: the Alzheimer's disease cooperative study. N Engl J Med 1997;336:1216-22.

[40] Mulnard RA, Cotman CW, Kawas C, van Dyck CH, Sano M, Doody R, et al. Estrogen replacement therapy for treatment of mild to moderate Alzheimer disease: a randomized controlled trial-Alzheimer's disease cooperative study. JAMA 2000;283:1007-15.

[41] Ismail MS, Dagerman K, Tariot PN, Abbott S, Kavanagh S, Schneider LS. National Institute of Mental Health Clinical Antipsychotic Trials of Intervention Effectiveness- Alzheimer's disease (CATIE-AD): baseline characteristics. Curr Alzheimer Res 2007; 4:325-35.

[42] Francois C, Sintonen H, Sulkava R, Rive B. Cost effectiveness of memantine in moderately severe to severe Alzheimer's disease: a markov model in Finland. Clin Drug Investig 2004;24:373-84.

[43] Dodge HH, Shen C, Pandav R, DeKosky ST, Ganguli M. Functional transitions and active life expectancy associated with Alzheimer disease. Arch Neurol 2003;60:253-9.

[44] National Institute for Health and Clinical Excellence. Final appraisal determination: donepezil, galantamine, rivastigmine (review) and memantine for the treatment of Alzheimer's disease. National Institute for Health and Clinical Excellence; 2006. Available at: http://www.nice. org.uk/nicemedia/pdf/Final_FAD_with_updated_audit_advice_sent_ to_C\&Cs_250506.pdf. Accessed January 26, 2009.

\section{Appendix}

\subsection{Excluded articles: ADL/functional dependence only}

Agüero-Torres H, Fratiglioni L, Guo Z, Viitanen M, von Strauss E, Winblad B. Dementia is the major cause of functional dependence in the elderly: 3-year follow-up data from a population-based study. Am J Public Health 1998;88:1452-6.

Andersen CK, Wittrup-Jensen KU, Lolk A, Andersen K, Kragh-Sørensen P. Ability to perform activities of daily living is the main factor affecting quality of life in patients with dementia. Health Qual Life Outcomes 2004;2:52.

Andrieu S, Rive B, Guilhaume C, Kurz X, Scuvée-Moreau J, Grand A, et al. New assessment of dependency in demented patients: impact on the quality of life in informal caregivers. Psychiatry Clin Neurosci 2007;61:234-42.

Armstrong M. Factors affecting the decision to place a relative with dementia into residential care. Nurs Stand 2000;14:33-7.

Barberger-Gateau P, Fabrigoule C, Helmer C, Rouch I, Dartigues JF. Functional impairment in instrumental activities of daily living: an early clinical sign of dementia? J Am Geriatr Soc 1999;47:456-62.

Bernardini B, Meinecke C, Zaccarini C, Bongiorni N, Fabbrini S, Gilardi C, et al. Adverse clinical events in dependent long-term nursing home residents. J Am Geriatr Soc 1993;41:105-11.

Breuer B, Anderson R. The relationship of tamoxifen with dementia, depression, and dependence in activities of daily living in elderly nursing home residents. Women Health 2000;31:71-85.

Breuer B, Trungold S, Martucci C, Wallenstein S, Likourezos A, Libow LS, et al. Relationships of sex hormone levels to dependence in activities of daily living in the frail elderly. Maturitas 2001;39:147-59.

Challis D, Mozley CG, Sutcliffe C, Bagley H, Price L, Burns A, et al. Dependency in older people recently admitted to care homes. Age Ageing 2000;29:255-60.

Chiu L, Tang KY, Liu YH, Shyu WC, Chang TP. Cost comparisons between family-based care and nursing home care for dementia. J Adv Nurs 1999;29:1005-12.

Demers L, Oremus M, Perrault A, Champoux N, Wolfson C. Review of outcome measurement instruments in Alzheimer's disease drug trials: psychometric properties of functional and quality of life scales. J Geriatr Psychiatry Neurol 2000;13:170-80.

Fagnani F, Lafuma A, Pechevis M, Rigaud AS, Traykov L, Seux ML, et al. Donepezil for the treatment of mild to moderate Alzheimer's disease in France: the economic implications. Dement Geriatr Cogn Disord 2004;17:5-13.

Ferm L. Changes of intellectual functioning and nursing dependency in institutionalized old people. Geron 1977;21:64-76.

Gitlin LN, Roth DL, Burgio LD, Loewenstein DA, Winter L, Nichols L, et al. Caregiver appraisals of functional 
dependence in individuals with dementia and associated caregiver upset: psychometric properties of a new scale and response patterns by caregiver and care recipient characteristics. J Aging Health 2005; 17:148-71.

Goldstein FC, Strasser DC, Woodard JL, Roberts VJ. Functional outcome of cognitively impaired hip fracture patients on a geriatric rehabilitation unit. J Am Geriatr Soc 1997;45:35-42.

González-Salvador T, Lyketsos CG, Baker A, Hovanec L, Roques C, Brandt J, et al. Quality of life in dementia patients in long-term care. Int J Geriatr Psychiatry 2000;15:181-9.

Herrmann N. Treatment of moderate to severe Alzheimer's disease: rationale and trial design. Can J Neurol Sci 2007;(suppl 1):S103-8.

Johnson N, Barion A, Rademaker A, Rehkemper G, Weintraub S. The Activities of Daily Living Questionnaire: a validation study in patients with dementia. Alzheimer Dis Assoc Disord 2004;18:223-30.

Jönsson L. Cost-effectiveness of memantine for moderate to severe Alzheimer's disease in Sweden. Am J Geriatr Pharmacother 2005;3:77-86.

Kurz X, Scuvee-Moreau J, Rive B, Dresse A. A new approach to the qualitative evaluation of functional disability in dementia. Int J Geriatr Psychiatry 2003;18:1050-5.

Kurz X, Scuvee-Moreau J, Vernooij-Dassen M, Dresse A. Cognitive impairment, dementia and quality of life in patients and caregivers. Acta Neurol Belg 2003;103:24-34.

Lim YM, Son GR, Song JA, Beattie E. Factors affecting burden of family caregivers of community-dwelling ambulatory elders with dementia in Korea. Arch Psychiatr Nurs 2008;22:226-34.

Mack JL, Patterson MB. An empirical basis for domains in the analysis of dependency in the activities of daily living (ADL): results of a confirmatory factor analysis of the Cleveland Scale for Activities of Daily Living (CSADL). Clin Neuropsychol 2006;20:662-77.

McConnell ES, Branch LG, Sloane RJ, Pieper CF. Natural history of change in physical function among long-stay nursing home residents. Nurs Res 2003;52:119-26.

Mehta KM, Yaffe K, Covinsky KE. Cognitive impairment, depressive symptoms, and functional decline in older people. J Am Geriatr Soc 2002;50:1045-50.

Moty C, Barberger-Gateau P, De Sarasqueta AM, Teare GF, Henrard JC. Risk adjustment of quality indicators in French long term care facilities for elderly people: a preliminary study. Rev Epidemiol Sante Publique 2003;51:327-38.

Nakaaki S, Murata Y, Sato J, Shinagawa Y, Tatsumi H, Hirono N, et al. Greater impairment of ability in the divided attention task is seen in Alzheimer's disease patients with depression than in those without depression. Dement Geriatr Cogn Disord 2007;23:231-40.

Newens AJ, Forster DP, Kay DW. Dependency and community care in presenile Alzheimer's disease. Br J Psychiatry 1995;166:777-82.

Pélissier C, Roudier M, Boller F. Factorial validation of the Severe Impairment Battery for patients with Alzheimer's disease: a pilot study. Dement Geriatr Cogn Disord 2002;13:95-100.

Razani J, Kakos B, Orieta-Barbalace C, Wong JT, Casas $\mathrm{R}, \mathrm{Lu} \mathrm{P}$, et al. Predicting caregiver burden from daily functional abilities of patients with mild dementia. J Am Geriatr Soc 2007;55:1415-20.

Riccio D, Solinas A, Astara G, Mantovani G. Comprehensive geriatric assessment in female elderly patients with Alzheimer disease and other types of dementia. Arch Gerontol Geriatr 2007;44(suppl 1):343-53.

Rigaud AS, Fagnani F, Bayle C, Latour F, Traykov L, Forette F. Patients with Alzheimer's disease living at home in France: costs and consequences of the disease. J Geriatr Psychiatry Neurol 2003;16:140-5.

Rogers JC, Holm MB, Burgio LD, Hsu C, Hardin JM, McDowell BJ. Excess disability during morning care in nursing home residents with dementia. Int Psychogeriatr 2000;12:267-82.

Samus QM, Rosenblatt A, Onyike C, Steele C, Baker A, Harper M, et al. Correlates of caregiver-rated quality of life in assisted living: the Maryland Assisted Living study. J Gerontol B Psychol Sci Soc Sci 2006;61:P311-4.

Scuvee-Moreau J, Kurz X, Dresse A, National Dementia Economic Study Group. The economic impact of dementia in Belgium: results of the National Dementia Economic Study (NADES). Acta Neurol Belg 2002;102:104-13.

Thomas $\mathrm{P}$, Ingrand $\mathrm{P}$, Lalloue $\mathrm{F}$, Hazif-Thomas $\mathrm{C}$, Billon $\mathrm{R}$, Viéban F, et al. Reasons of informal caregivers for institutionalizing dementia patients previously living at home: the Pixel study. Int J Geriatr Psychiatry 2004;19:127-35.

Thomas P, Lalloué F, Preux PM, Hazif-Thomas C, Pariel $\mathrm{S}$, Inscale R, et al. Dementia patients caregivers quality of life: the PIXEL study. Int J Geriatr Psychiatry 2006;21:50-6.

Timko C, Nguyen AT, Williford WO, Moos RH. Quality of care and outcomes of chronic mentally ill patients in hospitals and nursing homes. Hosp Community Psychiatry 1993;44:241-6.

Tran M, Bédard M, Molloy DW, Dubois S, Lever JA. Associations between psychotic symptoms and dependence in activities of daily living among older adults with Alzheimer's disease. Int Psychogeriatr 2003;15:171-9.

von Strauss E, Agüero-Torres H, Kåreholt I, Winblad B, Fratiglioni L. Women are more disabled in basic activities of daily living than men only in very advanced ages: a study on disability, morbidity, and mortality from the Kungsholmen Project. J Clin Epidemiol 2003;56:669-77.

Younger D, Martin GW. Dementia care mapping: an approach to quality audit of services for people with dementia in two health districts. J Adv Nurs 2000;32:1206-12.

\subsection{Excluded articles: Caregiver subjective burden only}

Bédard M, Kuzik R, Chambers L, Molloy DW, Dubois S, Lever JA. Understanding burden differences between men and women caregivers: the contribution of care-recipient problem behaviors. Int Psychogeriatr 2005;17:99-118. 
Farcnik K, Persyko MS. Assessment, measures and approaches to easing caregiver burden in Alzheimer's disease. Drugs Aging 2002;19:203-15.

Gort AM, Mingot M, Gomez X, Soler T, Torres G, Sacristán $\mathrm{O}$, et al. Use of the Zarit scale for assessing caregiver burden and collapse in caregiving at home in dementias. Int J Geriatr Psychiatry 2007;22:957-62.

Mafullul YM, Morriss RK. Determinants of satisfaction with care and emotional distress among informal carers of demented and non-demented elderly patients. Int J Geriatr Psychiatry 2000;15:594-9.

Murray J, Schneider J, Banerjee S, Mann A. EUROCARE: a cross-national study of co-resident spouse carers for people with Alzheimer's disease: part II-a qualitative analysis of the experience of caregiving. Int J Geriatr Psychiatry 1999;14:662-7.

Rivière S, Gillette-Guyonnet S, Andrieu S, Nourhashemi $\mathrm{F}$, Lauque S, Cantet $\mathrm{C}$, et al. Cognitive function and caregiver burden: predictive factors for eating behaviour disorders in Alzheimer's disease. Int J Geriatr Psychiatry 2002;17:950-5.

Serrano-Aguilar PG, Lopez-Bastida J, Yanes-Lopez V. Impact on health-related quality of life and perceived burden of informal caregivers of individuals with Alzheimer's disease. Neuroepidemiology 2006;27:136-42.

Thomas P, Clément JP, Hazif-Thomas C, Léger JM. Family, Alzheimer's disease and negative symptoms. Int J Geriatr Psychiatry 2001;16:192-202.

Tornatore JB, Grant LA. Burden among family caregivers of persons with Alzheimer's disease in nursing homes. Gerontologist 2002;42:497-506.

Wernet PA. Enabling caregivers to care for Alzheimer's patients at home. Caring 1991;10:28-30, 33-4.

\subsection{Excluded articles: General discussion of dependence, no specific measure/scale tested}

Altus DE, Engelman KK, Mathews RM. Using familystyle meals to increase participation and communication in persons with dementia. J Gerontol Nurs 2002;28:47-53.

Bigby C, Webber R, Bowers B, McKenzie-Green B. A survey of people with intellectual disabilities living in residential aged care facilities in Victoria. J Intellect Disabil Res 2008;52(pt 5):404-14.

Brooker DJ, Surr C. Dementia Care Mapping (DCM): initial validation of DCM 8 in UK field trials. Int J Geriatr Psychiatry 2006;21:1018-25.

Bullock R. Efficacy and safety of memantine in moderateto-severe Alzheimer disease: the evidence to date. Alzheimer Dis Assoc Disord 2006;20:23-9.

Butts JB, Rich KL. Acknowledging dependence: a MacIntyrean perspective on relationships involving Alzheimer's disease. Nurs Ethics 2004;11:400-10.

Colling KB. Passive behaviors in dementia: clinical application of the need-driven dementia-compromised behavior model. J Gerontol Nurs 1999;25:27-32.
Covinsky KE, Newcomer R, Fox P, Wood J, Sands L, Dane K, et al. Patient and caregiver characteristics associated with depression in caregivers of patients with dementia. J Gen Intern Med 2003;18:1006-14.

DeKosky ST, Orgogozo JM. Alzheimer disease: diagnosis, costs, and dimensions of treatment. Alzheimer Dis Assoc Disord 2001;15(suppl 1):S3-7.

Fernandez-Duque D, Black SE. Selective attention in early dementia of Alzheimer type. Brain Cogn 2008; 66:221-31.

Förstl H, Kurz A. Clinical features of Alzheimer's disease. Eur Arch Psychiatry Clin Neurosci 1999;249:288-90.

Franz CE, Barker JC, Kravitz RL, Flores Y, Krishnan S, Hinton L. Nonmedical influences on the use of cholinesterase inhibitors in dementia care. Alzheimer Dis Assoc Disord 2007;21:241-8.

Gagnon M, Rive B, Hux M, Guilhaume C. Cost-effectiveness of memantine compared with standard care in moderateto-severe Alzheimer disease in Canada. Can J Psychiatry 2007;52:519-26.

Ham RJ. Evolving standards in patient and caregiver support. Alzheimer Dis Assoc Disord 1999;13(suppl 2):S27-35.

Herrmann N. Treatment of moderate to severe Alzheimer's disease: rationale and trial design. Can J Neurol Sci 2007;34(suppl 1):S103-8.

Hirth VA, Davis B, Fridriksson J, Rorden C, Bonilha L. Cognitive performance and neural correlates of detecting driving hazards in healthy older adults. Dement Geriatr Cogn Disord 2007;24:335-42.

Howells R, Beats B. A dementia syndrome of dependency? Br J Psychiatry 1989;154:872-6.

Hughes CP, Berg L, Danziger WL, Coben LA, Martin RL. A new clinical scale for the staging of dementia. Br J Psychiatry 1982;140:566-72.

Isaac MG, Quinn R, Tabet N. Vitamin E for Alzheimer's disease and mild cognitive impairment. Cochrane Database Syst Rev 2008;3:CD002854.

Kolanowski A, Hoffman L, Hofer SM. Concordance of self-report and informant assessment of emotional well-being in nursing home residents with dementia. J Gerontol B Psychol Sci Soc Sci 2007;62:P20-7.

Korczyn AD. Drug trials in dementia: challenging ethical dilemmas. Curr Alzheimer Res 2007;4:468-72.

Nakaaki S, Murata Y, Sato J, Shinagawa Y, Tatsumi H, Hirono N, et al. Greater impairment of ability in the divided attention task is seen in Alzheimer's disease patients with depression than in those without depression. Dement Geriatr Cogn Disord 2007;23:231-40.

Nelson T, Fernandez JL, Livingston G, Knapp M, Katona C. Does diagnosis determine delivery? the Islington study of older people's needs and health care costs. Psychol Med 2004;34:147-55.

Netuveli G, Blane D. Quality of life in older ages. Br Med Bull 2008;85:113-26.

Rao V, Spiro J, Samus QM, Steele C, Baker A, Brandt J, et al. Insomnia and daytime sleepiness in people with 
dementia residing in assisted living: findings from the Maryland Assisted Living Study. Int J Geriatr Psychiatry 2008;23:199-206.

Sanders S, Power J. Roles, responsibilities, and relationships among older husbands caring for wives with progressive dementia and other chronic conditions. Health Soc Work 2009;34:41-51.

Scuvee-Moreau J, Kurz X, Dresse A, National Dementia Economic Study Group. The economic impact of dementia in Belgium: results of the National Dementia Economic Study (NADES). Acta Neurol Belg 2002;102:104-13.

Sormunen S, Topo P, Eloniemi-Sulkava U, Räikkönen O, Sarvimäki A. Inappropriate treatment of people with dementia in residential and day care. Aging Ment Health 2007;11:246-55.

Thornton A, Hatton C, Tatham A. Dementia Care Mapping reconsidered: exploring the reliability and validity of the observational tool. Int $\mathrm{J}$ Geriatr Psychiatry 2004;19:718-26.

Välimäki T, Vehviläinen-Julkunen K, Pietilä AM. Diaries as research data in a study on family caregivers of people with Alzheimer's disease: methodological issues. J Adv Nurs 2007;59:68-76.

\subsection{Remaining articles from MEDLINE search}

Baird A. Fine tuning recommendations for older adults with memory complaints: using the Independent Living Scales with the Dementia Rating Scale. Clin Neuropsychol 2006;20:649-61.

Brickman AM, Riba A, Bell K, Marder K, Albert M, Brandt $\mathrm{J}$, et al. Longitudinal assessment of patient dependence in Alzheimer disease. Arch Neurol 2002;59:1304-8.

Caro J, Ward A, Ishak K, Migliaccio-Walle K, Getsios D, Papadopoulos G, et al. To what degree does cognitive impairment in Alzheimer's disease predict dependence of patients on caregivers? BMC Neurol 2002;2:6.

Cotter EM, Burgio LD, Stevens AB, Roth DL, Gitlin LN. Correspondence of the functional independence measure (FIM) self-care subscale with real-time observations of dementia patients' ADL performance in the home. Clin Rehabil 2002;16:36-45.

Dijkstra A, Brown L, Havens B, Romeren TI, Zanotti R, Dassen T, et al. An international psychometric testing of the care dependency scale. J Adv Nurs 2000;31:944-52.
Dijkstra A, Buist G, Moorer P, Dassen T. Construct validity of the Nursing Care Dependency scale. J Clin Nurs 1999;8:380-8.

Dijkstra A, Sipsma D, Dassen T. Predictors of care dependency in Alzheimer's disease after a two-year period. Int J Nurs Stud 1999;36:487-95.

Hancock GA, Woods B, Challis D, Orrell M. The needs of older people with dementia in residential care. Int J Geriatr Psychiatry 2006;21:43-9.

Hoe J, Hancock G, Livingston G, Orrell M. Quality of life of people with dementia in residential care homes. Br J Psychiatry 2006;188:460-4.

Holtzer R, Wegesin DJ, Albert SM, Marder K, Bell K, Albert $\mathrm{M}$, et al. The rate of cognitive decline and risk of reaching clinical milestones in Alzheimer disease. Arch Neurol 2003;60:1137-42.

Knopman DS, Berg JD, Thomas R, Grundman M, Thal LJ, Sano M. Nursing home placement is related to dementia progression: experience from a clinical trial-Alzheimer's Disease Cooperative study. Neurology 1999;52:714-8.

Sarazin M, Stern Y, Berr C, Riba A, Albert M, Brandt J, et al. Neuropsychological predictors of dependency in patients with Alzheimer disease. Neurology 2005;64:1027-31

Scherer RK, Scarmeas N, Brandt J, Blacker D, Albert MS, Stern Y. The relation of patient dependence to home health aide use in Alzheimer's disease. J Gerontol A Biol Sci Med Sci 2008;63:1005-9.

Stern Y, Albert SM, Sano M, Richards M, Miller L, Folstein M, et al. Assessing patient dependence in Alzheimer's disease. J Gerontol 1994;49:M216-22.

Winblad B, Poritis N. Memantine in severe dementia: results of the 9 M-Best Study (benefit and efficacy in severely demented patients during treatment with memantine). Int J Geriatr Psychiatry 1999;14:135-46.

Woods B, Thorgrimsen L, Spector A, Royan L, Orrell M. Improved quality of life and cognitive stimulation therapy in dementia. Aging Ment Health 2006;10:219-26.

Zhu CW, Leibman C, McLaughlin T, Scarmeas N, Albert $\mathrm{M}$, Brandt J, et al. The effects of patient function and dependence on costs of care in Alzheimer's disease. J Am Geriatr Soc 2008;56:1497-503.

Zhu CW, Leibman C, McLaughlin T, Zbrozek AS, Scarmeas N, Albert M, et al. Patient dependence and longitudinal changes in costs of care in Alzheimer's disease. Dement Geriatr Cogn Disord 2008;26:416-23. 